Отримано: 23 квітня 2020 р.

Прорецензовано: 12 травня 2020 р.

Прийнято до друку: 19 травня 2020 р.

e-mail: gkolomiets@karazin.ua

omelentsova@karazin.ua

DOI: $10.25264 / 2311-5149-2020-17(45)-16-21$
Коломієць Г. М., Меленцова О. В., Чередниченко А. П. Рентоорієнтована поведінка як перешкода посткризового господарського розвитку. Наукові записки Національного університету «Острозька академія». Серія «Економіка» : науковий журнал. Острог : Вид-во НаУОА, червень 2020. № 17(45). С. 16-21.

\author{
Коломісць Ганна Миколаївна, \\ доктор економічних наук, професор, \\ професор кафедри економічної теорії та економічних методів управління \\ Харківського національного університету імені В.Н. Каразіна \\ Меленцова Ольга Володимирівна, \\ кандидат економічних наук, \\ дочент кафедри економічної теорії та економічних методів управління \\ Харківського національного університету імені В.Н. Каразіна
}

Чередниченко Ангеліна Петрівна,

магістр економіки

\title{
РЕНТООРІЕНТОВАНА ПОВЕДІНКА
}

ЯК ПЕРЕШКОДА ПОСТКРИЗОВОГО ГОСПОДАРСЬКОГО РОЗВИТКУ

Подолання кризи, виведення національної господарської системи з депресії в умовах суттєвих інтенсивних змін світового середовища потребує виокремлення найбільш небезпечних перешкод иього процесу. Науковці, експерти, політики доводять, що увага має бути привернута, перш за все, до інституційних пасток поширених в суспільстві. Дослідження, спрямоване на виявлення укорінених иінностей в українському суспільстві свідчтьь про розповсюдження рентоорієнтованої поведінки. Пошук ренти полягає в намаганні отримати особливу, привілейовану позицію, монополізувати доступ до актуальних ресурсів.

Ключові слова: рентоорієнтована поведінка, подолання кризи національної господарської системи.

Коломиец Анна Николаевна,

доктор экономических наук, профессор,

профессор кафедры экономической теории и экономических методов управления

Харьковского национального университета имени В.Н. Каразина

Меленцова Ольга Владимировна,

кандидат экономических наук,

доцент кафедры экономической теории и экономических методов управления

Харьковского национального университета имени В.Н. Каразина

Чередниченко Ангелина Петровна,

магистр экономики

\section{РЕНТООРИЕНТОВАНОЕ ПОВЕДЕНИЕ КАК ПОМЕХА ПОСТКРИЗИСНОГО ХОЗЯЙСТВЕННОГО РАЗВИТИЯ}

Преодоление кризиса, вывода национальной хозяйственной системы из депрессии в условиях существенных интенсивных изменений мировой среды требует выделения наиболее опасных препятствий этого процесса. Ученые, эксперты, политики доказывают, что внимание должно быть привлечено, прежде всего, к институциональным ловушкам распространенных в обществе. Исследование, направленное на выявление укоренившихся иенностей в украинском обществе свидетельствует о распространении рентоориентованого поведения. Поиск ренты заключается в попьтке получить особую, привилегированную позицию, монополизировать доступ к актуальным ресурсов.

Ключевые слова: рентоориентована поведение, преодоление кризиса начиональной хозяйственной системы. 


\section{Ganna Kolomiets,}

D. Sc. (Economics), Professor of the Department of Economic Theory and Economic Methods of Management, V. N. Karazin Kharkiv National University

Olga Melentsova,

PhD in Economics, Associate Professor, Department of Economic Theory and Economic Management Methods V. N. Karazin Kharkiv National University

\section{Angelina Cherednichenko,}

Master of Economics

\section{RENT-BASED BEHAVIOUR AS A HINDRANCE TO POST-CRISIS ECONOMIC DEVELOPMENT}

Overcoming the crisis and lifting the national economic system out of depression in the face of significant and intensive changes in the world environment requires highlighting the most dangerous obstacles to this process. Scientists, experts, politicians argue that attention should be drawn, first and foremost, to the institutional traps that are prevalent in society. A study aimed at identifying deep-rooted values in Ukrainian society shows the spread of rent-oriented behaviour.

All subjects of rental relations are characterized by rent-oriented behavior due to rental interest, i.e., actions aimed at obtaining rental income. In the framework of institutionalism, the study of rental relations is much more complicated.

Not only rental incomes appear in the system, the formation and appropriation of which occurs as a result of natural factors, but there are various types of rents that are created artificially as a result of negative incentives for economic agents.

The process of formation and appropriation of rent is possible when the economic agent reaches a special position or monopoly power and has "negative social value". The net loss of society from rent-seeking behavior is the cost of resources by economic agents to obtain rental income. Rent-oriented behavior can take various forms: persuasion, the use of financial resources, administrative and political tools, etc. The search for rent is an attempt to gain a special, privileged position, to monopolize access to current resources.

Keywords: rent-oriented behaviour, overcoming the crisis of the national economic system, innovative development, digitization.

Політики, експерти, науковці все більше усвідомлюють, що подолання господарської кризи, каталізатором якої стало розповсюдження вірусної інфекції, потребує значних зусиль для створення нових можливостей сталого зростання господарської системи, переформатування структури економіки, подолання залежності від попереднього розвитку [1,2]. Ключовою передумовою цього процесу стає виявлення і усунення перешкод для його здійснення. Методологічною основою систематизації перешкод стала інституційна економіка та компаративна аналітика. А. Медісон використовуючи статистичні дані стосовно окремих країн, зробив порівняльний аналіз, співставляючи їх розвиток впродовж двох століть за показником ВВП [3]. Переведені в графічну форму вони дозволили виявити певні тенденції:

По-перше, країни досить чітко діляться на дві групи, між якими виникає очевидний розрив, який у ході історичного розвитку може збільшуватися.

По-друге, кожна група країн рухається за своєю траєкторією А чи В. Економіки всіх країн зростають, але різними темпами. Швидкість зростання країн траєкторії А значно вище ніж країн траєкторії В, яка обумовлена більш високою якістю інститутів в траєкторії А.

По-третє, країни дуже рідко залишають свою траєкторію і переміщається на іншу. В XX столітті змінили траєкторію Японія, Південна Корея, Сінгапур і Тайвань. Існує сила, яка утримує країни в траєкторії А чи В. [4].

Так з'явилося розуміння того, що існує залежність від попереднього розвитку, яка не завжди відповідає виникаючим викликам.

Досить тривалий час переважали уявлення, що більш ефективні правила повинні перемагати менш ефективні та історично все виправляється, країни мають зближуватися між собою: інститути, набори правил повинні ставати все більш схожими. Ця гіпотеза була висунута в 1950-х роках, а до 1980-х років вона була спростована як фактично, так і теоретично. Країни не зближуються одна з одною за рівнем розвитку та за складом інститутів. Більш того, розриви між ними зростають.

Було проведено дослідження, фінансування якого здійснив Всесвітній банк. Група експертів під керівництвом Ф. Кіфер і М. Ширлі проаналізувала 84 країни за часткою валового доходу на душу населення 3 метою з'ясування, які чинники найбільше впливають на розвиток країни [5]. Вийшло, що такі фактори, які зазвичай відносять до засобів економічної політики: відсоткова ставка, податки та інші впливають дуже мало. Набагато сильніше впливають неформальні правила, цінності і поведінкові установки, які поширені в країні: влада закону, недотримання урядом своїх зобов'язань, рівень корупції, якість бюрократії.

Країна, яка має не найновітнішу економічну політику, але просту, ясну, міцну систему правил, розвивається значно краще, ніж країна, де уряд проводить економічну політику, яка не сприймається значною 
його частиною, оскільки не враховує їх інтереси, формує канали перерозподілу суспільного багатства на користь «зацікавлених осіб» - розширено відтворюючи рентоорієнтовану поведінку. Це набуває особливого значення при вибудові антикризової та посткризової траєкторії господарського розвитку.

Термін (rent seeking) вперше був використаний для визначення відповідної діяльності в роботі А. Крюгер «Політична економія рентоорієнтованого суспільства» [6]. На феномен пошуку ренти зробив акцент Г. Таллок в рамках теорії суспільного вибору у зв'язку з екстерналіями та діяльністю держави [7].

Пошук ренти став ознакою не тільки національної економіки, але й глобальної господарської системи, яка демонструє виразні ознаки перетворення ринкової моделі капіталізму в рентну. На домінуючі позиції вилучення ресурсів в умовах млявого економічного функціонування, як нової глобальної норми, поступово замість націленості на підприємницькі прибутки виходить фактор рентних доходів, що в довгому історичному часі, як показує в своїх розрахунках Т. Пикетті, $є$ нормальним станом природного капіталізму [8, с. 350-358]. Увагу суспільства до проблеми рентного капіталізму і його негативного впливу на суспільні відносини привернув М. Вольф в Financial Times в вересні 2019 р. [9].

В сучасній економіці рентоорієнтована поведінка може набувати різноманітних форм, але основний засіб досягти ренти в усіх випадках полягає в отриманні монопольних прав на актуальні ресурси, особливої, привілейованої позиції. Вона утворює інституційну пастку, подолати яку досить складно і потребує певного часу [10, с. 201].

Рентоорієнтована поведінка вкрай негативно впливає на національну економіку:

- напряму відволікає ресурси з відтворення суспільного продукту;

- обмежує доступність чи здорожує кредитні ресурси;

- в умовах нечіткої специфікації прав власності підвищує інвестиційні ризики.

Рентоорієнтована поведінка укорінюються внаслідок того, що

- фіксовані початкові витрати дають можливість отримати набагато більшу і довготривалу ренту;

- отримання ренти стає засобом конкуренції, змушуючи більшу кількість господарських суб'єктів долучатися до його використання;

- поширення рентоорієнтованої поведінки, зменшує ймовірність ії викриття та покарання.

В доповіді, підготовленій експертами Світового банку на основі аналізу даних та досліджень, проведених Інститутом економічних досліджень та Командою політичних консультацій в рамках Програми реформування системи управління в Україні, яка фінансується Департаментом міжнародного розвитку Великої Британії (UKAid) було доведено рентоорієнтованість господарської системи України, яка була ідентифікована як «кумівський капіталізм» 3 подальшим його дрейфом в “капіталізм для своїх”. Це така модель економічного врядування, в якій незначна кількість компаній, які тісно пов'язані з політикумом, користується превагами, до яких інші компанії не мають доступу [11]. Рентоорієнтована поведінка господарюючих суб'єктів укорінилась як формальна норма. Наслідком стало неефективний розподіл ресурсів, обмеження конкуренції, збільшення економічних витрат та звуження економічних можливостей розвитку суспільства.

Питома вага компаній з політичними зв'язками в українській економіці незначна та становить від 0,5\% до $2 \%$ загальної кількості фірм в Україні, але за параметрами зайнятості та обороту їх доля сягає від 15\% до $20 \%$ [11].

Існує сильна негативна кореляція між наявністю політичних зв'язків та продуктивністю компаній. Вони повільніше зростають і платять менше податків порівняно з аналогічними політично незалежними фірмами. За оцінками експертів така модель української економіки уповільнює її зростання на 1-2\% на рік [11]. Склалися засоби відводу ресурсів, які отримують форму ренти. (Рис.1)

Господарська система екстрактивного типу обумовлює недовіру до влади, несприйняття запроваджуваних господарських перетворень, а відповідно ї їх неефективність. Легітимність і імплементацію формальним правилам забезпечують неформальні норми. «Якщо формальне утворення правил шляхом прямих дій занадто відхиляється від траєкторії еволюції неформальних норм, негативні наслідки не затримаються», - С.Хедлунд [12, с.15]. Дослідженню ролі інститутів, які можуть стати перешкодою економічного розвитку приділяють увагу Д. Норт, О. Аузан, С. Хедлунд, Е. Райнерт, Д. Аджемоглу Д. Робинсон [13]. Широко відома методика Р. Інглхарта з оцінки впливу цінностей на економіку. Реалізація проекту «Всесвітнє дослідження цінностей» (The world value ssurvey) під керівництвом Р. Інглхарта дозволила дослідити зміни, що відбуваються в сучасному світі. Міжкультурна варіативність пояснюється за допомогою 2 параметрів, складених з альтернатив:

1) Традиційні цінності /секулярно-раціональні цінності;

2) Цінності виживання/ цінності самовираження. 


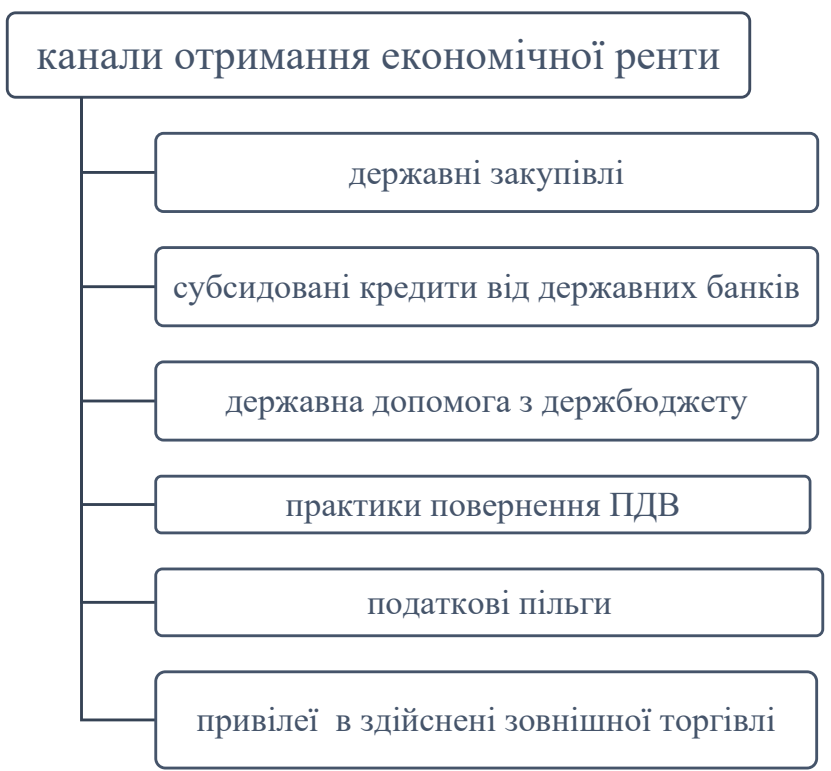

Рис. 1. Канали отримання економічної ренти в Україні

Домінування в тому чи іншому суспільстві однієї з альтернативних цінностей, їх взаємозв'язку впливає на господарський розвиток, і їх аналіз стає важливим інструментом прогнозування його провідних тенденцій [3].

«Відповідно до переміщення трудових ресурсів з аграрного сектору в індустріальний у світогляді людей, як правило, відбувається зрушення від традиційних цінностей до секулярно-раціональних. Пізніше, коли переважний розвиток отримує вже не індустріальний сектор, а сектор послуг, відбувається другий масштабний зсув у сфері ціннісних орієнтацій - перехід від цінностей виживання до цінностей самовираження [3, с.18].

Можливий і зворотній рух. В Україні внаслідок економічних і політичних потрясінь відбувся зсув цінностей від секулярно-раціональних до традиційних і від цінностей самовираження до виживання. Відбулися зміни в поведінкових установках і мотивації господарюючих суб'єктів, що стає перешкодою подоланню кризи та посткризовому розвитку. Дослідити ці зміни дозволяє використання аналітично-порівняльної методології Г. Хофстеде зі шкалою від 0 до 100 за шістьма амбівалентно вибудуваними індикаторами (Рис. 2).

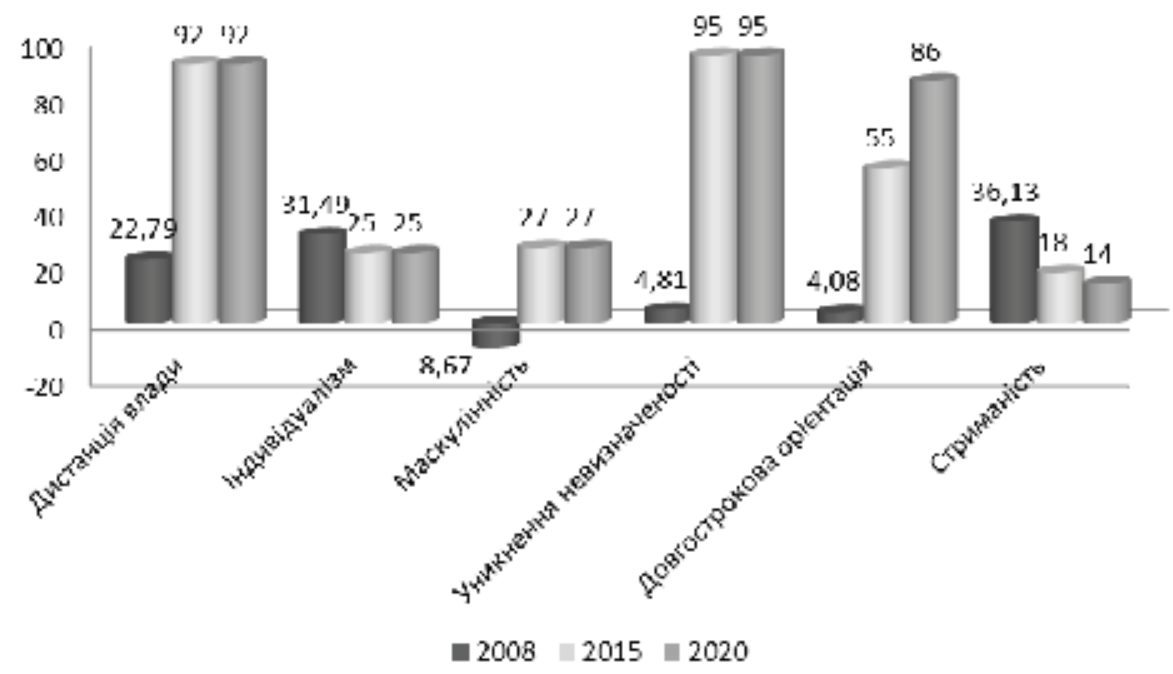

Рис. 2. Зміна параметрів поведінкових установок в Україні за типологісю Г. Хофстеде (2020-оцінка) $[14 ; 15 ; 16]$

За останнє десятиліття в Україні значно зросла дистанція влади. Культури з високою дистанцією влади виробляють правила, механізми, ритуали, які утворюють і відтворюють ієрархічні відносин між ії членами. 
Збільшення дистанції влади свідчить про зростання владної диференціації, розбіжності між людьми з різними власними повноваженнями, відчуження громадян від реалізації функцій суспільного управління. Україна з показником 92 має високу дистанцію влади, що свідчить і про недовіру до здійснюваних нею заходів.

I так не дуже високий для країн з ринковою економікою показник індивідуалізму закріпився в останні роки на рівні попереднього періоду. Це означає, що можливість індивідуального вибору досить обмежена. Місце особи в суспільстві усталено. Закріплюється усвідомлення, що особисті інтереси мають пріоритет навіть в критичних для суспільства умовах, і цілком узгоджується з намагання отримати високий дохід 3 «місця» будь-якою ціною.

Суттєво збільшився показник «маскулінність» - це ступінь, в якій застосування сили підтримується в суспільстві. Цей показник відображає просування в напрямку твердості, зосередженості на власних цілях, наполегливості, самовпевненості, змагальності. Мова йде про те, що є домінуючим мотивом в суспільстві: конкуренція або солідарність і кооперація. За даним індикатором Україні змінилась на більш ніж 35 пунктів в бік маскулінності.

Індекс «уникнення невизначеності» відображає здатність суспільства справлятися з тривогою і стресами, викликаними непередбачуваними змінами і навпаки бажанням мати сталі звички, ритуали та знати правду. Високі показники (95), що підтверджуються останні десять років, свідчать про відчуття загроз неоднозначних ситуацій, прагнення до стабільності. При швидкому збільшенні цього показника, відставанні в вибудовуванні засобів адаптації до невизначеності спостерігається намагання їх подолати шляхом створення будь-яким чином власного «резервного фонду», прагнення знайти джерело швидких наддоходів, щоб убезпечити собі «подушку безпеки».

По параметру «довгострокова орієнтація» ми маємо 86. Цей параметр відображає те, наскільки суспільство проявляє незадоволення сьогоденням і стратегічно орієнтується на майбутнє, прагне змін.

Індекс «поблажливість/стриманість» в Україні становить 14, тобто незначна кількість осіб вважає себе щасливими, превалює відчуття безпорадності. Суспільству властива схильність до песимізму, невеликий акцент робиться на вільний час та задоволення зростаючих потреб. Стриманість, як поведінкова установка, виходить з того, що життя складне, обов'язок, а не свобода $є$ нормальним станом буття.

Наведена динаміка поведінкових установок: значна дистанція влади, намагання уникнення невизначеності, довгострокова орієнтація та інші, свідчать що рентоорієнтована поведінка укорінюється і відтворюється. Зміни поведінкових установок інтегрується в зміщенні сенсів життя і засобів їх забезпечення. В дослідженні GfK Ukraine «Як змінюються цінності українців?», які були оприлюднені на конференції «Цінності та модернізація», було зазначено, що перетворення господарської системи може наразитися на ризики стосовно змінюваних цінностей: зокрема «Прагнення швидкого збагачення та набуття статусу (завдяки зовнішнім обставинам, а не чесній праці)» [17] тобто рентоорієнтованість стала властивістю українського суспільства.

Загальнонаціональне дослідження проведене Фондом «Демократичні ініціативи» імені Ілька Кучеріва спільно з соціологічною службою Центру Разумкова з 6 по 11 грудня 2019 року в усіх регіонах України виявила щодо реалізації необхідних реформ діяльність уряду громадяни оцінюють переважно негативно (45\% - негативні оцінки, 36\% - позитивні), так само як і діяльність Верховної Ради (50\% негативних оцінок і $31 \%$ - позитивних). А найбільший опір реформам, на думку громадян, чинять олігархи (51\%) та бюрократія, чиновники (43\%). Порівняно з минулим роком в уявленнях українців щодо рушіїв реформ відбулися істотні зміни: значно зменшилося визнання як рушіїв реформ країн Заходу (з $25 \%$ до $12 \%$ ) та МВФ і Світового банку (з 24\% до 12\%) [18].

Загалом, реалізація антикризових заходів та програм розвитку господарської системи в посткризовий період, структурні перетворення на основі запровадження інноваційних чинників стримуються формалізованою рентоорієнтованою моделлю на макро та мезо рівнях і неформальними нормами на мікро рівні - поведінковими установками спрямованими на пошук ренти.

Рентоорієнтована поведінка отримала широке розповсюдження, перетворюючи господарські системи в так звані «рентні економіки» різного виду в залежності від джерел утворення ренти: зовнішніх чи внутрішніх. Господарська система України - «рентна економіка» в подвійному сенсі, оскільки стає джерелом ренти не тільки для внутрішніх, але й для зовнішніх рентопошукачів. В цих умовах подолання сучасної кризи без глибинних скорегованих перетворень формальних та неформальних інститутів посткризовий розвиток знаходиться під загрозою.

\section{Література:}

1. Nouriel Roubini. (2020). This is what the economic fallout from coronavirus could look like https://www. weforum.org/agenda/2020/04/depression-global-economy-coronavirus/ 
Nouriel Roubini. This is what the economic fallout from coronavirus could look like https://www.weforum.org/ agenda/2020/04/depression-global-economy-coronavirus/. [in English].

2. This is how much the coronavirus will cost the world's economy, according to the UN https://www.weforum.org/ agenda/2020/03/coronavirus-covid-19-cost-economy-2020-un-trade-economics-pandemic

This is how much the coronavirus will cost the world's economy, according to the UN https://www.weforum.org/ agenda/2020/03/coronavirus-covid-19-cost-economy-2020-un-trade-economics-pandemic. [in English].

3. Maddison, A. (2007). The World Economy. Vol. 1: A Millennial Perspective; Vol. 2: Historical Statistics. New Dehli.

Maddison, A. (2007). The World Economy. Vol. 1: A Millennial Perspective; Vol. 2: Historical Statistics. New Dehli, 2007. [in English].

4. Аузан А. А. «Эффект колеи». Проблема зависимости от траектории предшествующего развития - эволюция гипотез. Вестник Московского университета. Серия 6. Экономика. 2015. № 1.

Auzan, A. A., (2015). «Jeffekt kolei». Problema zavisimosti Ot traektorii predshestvujushhego razvitija - Jevoljucija gipotez. VESTN. MOSK. UN-TA. SER. 6. JeKONOMIKA. № 1. [in Ukrainian].

5. Keefer, Ph. (2000). Formal Versus Informal Institution Economic Development, Institution, Contracts and Organization / Ph. Keefer, M. Shirley // Perspectives from New Institutional Economics. Edward Elgar

Keefer, Ph. (2000). Formal Versus Informal Institution Economic Development, Institution, Contracts and Organization / Ph. Keefer, M. Shirley // Perspectives from New Institutional Economics. Edward Elgar. [in English].

6. Krueger, A. (1974). The political economy of the rent-seeking society. American Economic Review. Vol. 64, N 3. P. 291-303.

Krueger, A. (1974). The political economy of the rent-seeking society. American Economic Review. Vol. 64, N 3. P. 291-303. [in English].

7. Tullock, G. (1988). Rents and rent seeking. The political economy of rent seeking / Eds. by C. Rowley, R. Tollison, G. Tullock. Boston.

Tullock, G. (1988). Rents and rent seeking. The rolitical economy of rent seeking / Eds. by C. Rowley, R. Tollison, G. Tullock. Boston. [in English].

8. Пикетти Т. Капитал в XXI веке. Москва : Ад Маргинем Пресс, 2015. 592 с.

Piketti T. (2015). Kapital v XXI veke. M.: Ad Marginem Press, 592 s. [in Ukrainian].

9. Martin, Wolf. (2019). Why rigged capitalism is damaging liberal democracy. Financial Times. September, 18. https://www.ft.com/content/5a8ab27e-d470-11e9-8367-807ebd53ab77

Martin, Wolf. (2019). Why rigged capitalism is damaging liberal democracy. Financial Times. September, 18. https://www.ft.com/content/5a8ab27e-d470-11e9-8367-807ebd53ab77. [in English].

10. Институциональная экономика: Новая институииональная экономическая теорія / под ред. А. А. Аузана. Москва : ИНФРА-М, 2011. 447 с.

Institucional'naja jekonomika: Novaja instituiional'naja jekonomicheskaja teorija: / Pol red. A. A. Auzana. M.: INFRA-M, 2011. 447 s. [in Ukrainian].

11. Сату Кахконен. Яка вартість кумівського капіталізму для України? URL: https://www.worldbank.org/uk/ news/opinion/2018/03/15/what-is-the-cost-of-crony-capitalism-for-ukrainel.

Satu Kahkonen. Jaka vartist' kumivs'kogo kapitalizmu dlja Ukraïni? https://www.worldbank.org/uk/news/ opinion/2018/03/15/what-is-the-cost-of-crony-capitalism-for-ukraine $\backslash$ [in Ukrainian].

12. Хедлунд С. Невидимые руки...Способы объяснения системного провала. Москва : Изд.дом ВШЭ. 2015,424 с.

Hedlund S. Nevidimye ruki...Sposoby ob\#jasnenija sistemnogo provala. M.: Izd.dom VShJe. 2015, 424s. [in Ukrainian].

13. Коломієць Г. М., Алієва Е. І. Глобальний соціальний капітал як фактор виходу на траєкторію сталого господарського розвитку. Бізнес інформ. 2016. №11. С.19-23.

Kolomiєc' G.M., Aliєva E.I. Global'nij social'nij kapital jak faktor vihodu na tra€ktoriju stalogo gospodars'kogo rozvitku Biznes inform. 2016, №11. S.19-23. [in Ukrainian].

14. The Hofstede Centre. URL: http://geert-hofstede.com.

The Hofstede Centre. URL: http://geert-hofstede.com. [in English].

15. Hofstede G. Values Survey Module 2008 (VSM 08) // G. J. Hofstede, M. Minkov, H. Vinken. URL : www/ URL:htpp//geerthofstede.nl. - 08.01.08. - Загол. с екрана

Hofstede G. Values Survey Module 2008 (VSM 08) // G. J. Hofstede, M. Minkov, H. Vinken. - Rezhim dostupa:www/ URL:htpp//geerthofstede.nl. - 08.01.08. - Zagol. s ekrana [in English].

11. Hofstede, Geert (2011). Dimensionalizing Cultures: The Hofstede Model in Context. Online Readings in Psychology and Culture, Unit 2. URL: http://scholarworks.gvsu.edu/orpc/vol2/iss1/8.

Hofstede, Geert (2011). Dimensionalizing Cultures: The Hofstede Model in Context. Online Readings in Psychology and Culture, Unit 2. URL: http://scholarworks.gvsu.edu/orpc/vol2/iss1/8. [in English].

12. «Як змінюються цінності українців?» URL: https://www.gfk.com/uk-ua/rishennja/news/materialiprezentaciji-gfk-z-konferenciji-cinnosti-ta-modernizacija/.

«Jak zminjujut'sja cinnosti ukraïnciv?» https://www.gfk.com/uk-ua/rishennja/news/materiali-prezentaciji-gfk-zkonferenciji-cinnosti-ta-modernizacija/ [in Ukrainian].

13. Реформи в Україні: громадська думка населення-2019. URL: https://dif.org.ua/article/reformi-v-ukrainigromadska-dumka-naselennya-2019

Reformi v Ukraïni: gromads'ka dumka naselennja-2019. URL: https://dif.org.ua/article/reformi-v-ukrainigromadska-dumka-naselennya-2019 [in Ukrainian]. 